This item was submitted to Loughborough's Research Repository by the author.

Items in Figshare are protected by copyright, with all rights reserved, unless otherwise indicated.

\title{
Factors influencing performance in the Hecht vault and implications for
} modelling

\section{PLEASE CITE THE PUBLISHED VERSION}

http://dx.doi.org/10.1016/j.jbiomech.2004.02.039

PUBLISHER

(C) Elsevier

VERSION

AM (Accepted Manuscript)

LICENCE

CC BY-NC-ND 4.0

\section{REPOSITORY RECORD}

King, Mark A., and Maurice R. Yeadon. 2019. "Factors Influencing Performance in the Hecht Vault and Implications for Modelling". figshare. https://hdl.handle.net/2134/6629. 
This item was submitted to Loughborough's Institutional Repository (https://dspace.lboro.ac.uk/) by the author and is made available under the following Creative Commons Licence conditions.

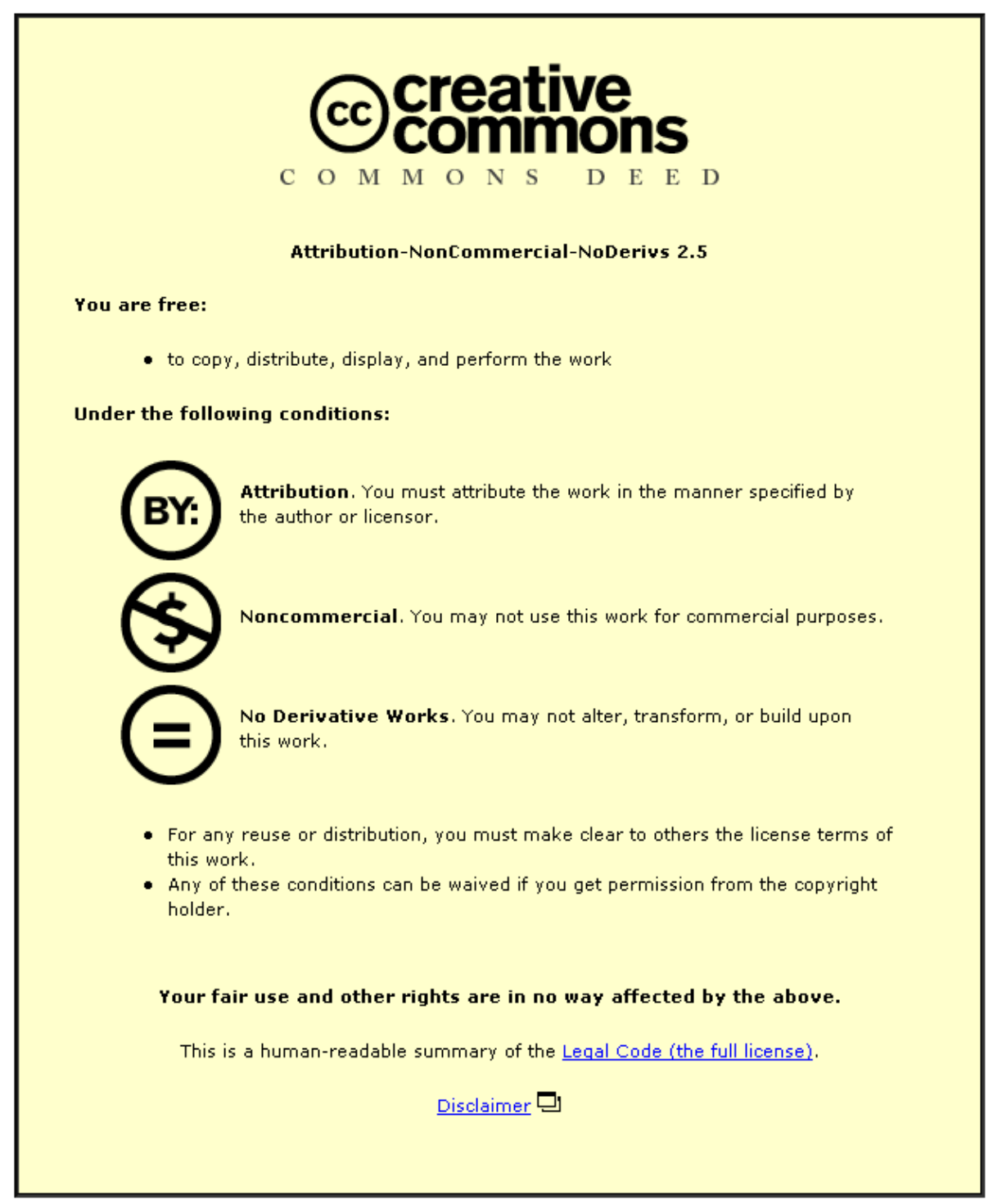

For the full text of this licence, please go to: http://creativecommons.org/licenses/by-nc-nd/2.5/ 


\title{
Factors influencing performance in the Hecht vault and implications for modelling
}

\author{
Mark A. King and Maurice R. Yeadon \\ School of Sport and Exercise Sciences, Loughborough University, Loughborough LE11 3TU, UK
}

\begin{abstract}
This paper investigated the factors that influence Hecht vault performance and assessed the level of model complexity required to give an adequate representation of vaulting. A five-segment planar simulation model with a visco-elastic shoulder joint and a torque generator at the shoulder joint was used to simulate the contact phase in vaulting. The model was customised to an elite gymnast by determining subject-specific segmental inertia and joint torque parameters. The simulation model was matched to a performance of the Hecht vault by varying the visco-elastic characteristics of the shoulders and the arm-horse interface and the activation time history of the shoulder torque generator until the best match was found. Perturbing the matching simulation demonstrated that appropriate initial kinematics are necessary for a successful performance. Fixing the hip and knee angles at their initial values had a small effect with $3^{\circ}$ less rotation. Applying shoulder torque during the contact phase also had a small effect with only a $7^{\circ}$ range in landing angles. Excluding the hand segment from the model was found to have a moderate effect with $15^{\circ}$ less rotation and the time of contact reduced by 38\%. Removing shoulder elasticity resulted in $50^{\circ}$ less rotation. The use of a five-segment simulation model confirmed that the use of shoulder torque plays a minor role in vaulting performance and that having appropriate initial kinematics at touchdown is essential. However, factors such as shoulder elasticity and the hands which have previously been ignored also have a substantial influence on performance.
\end{abstract}

Keywords : gymnastics, simulation model

\section{Introduction}

The Hecht vault is an unusual vault in modern day gymnastics as forwards rotation during preflight (before contact with the horse) is reversed during horse contact resulting in backwards rotation during postflight (after takeoff from the horse). The Hecht vault was the compulsory vault in Men’s Artistic Gymnastics during the Olympic cycle 1993-1996. During that period a number of amendments were made to the F.I.G. specifications for the vault. In the original version of the regulations governing compulsory exercises (F.I.G., 1993) the body angle above the horizontal at horse contact was required to be at least $30^{\circ}$ but subsequently this criterion angle was reduced to $20^{\circ}$ to facilitate more dynamic performances (Fink and Zschoke, 1994).

The Hecht vault has received some attention in recent years as a consequence of it being a compulsory vault. For example 27 performances of the Hecht vault at the 1993 Canadian National Championships were analysed (Yeadon et al., 1998). They found that gymnasts performing the Hecht vault had longer, lower and faster preflights with slower rotation at horse contact compared to handspring somersault vaults. Only very simple two-segment models have been developed for the Hecht vault (Sprigings and Yeadon, 1997; King et al., 1999)). These models have been used to give a basic understanding of the mechanics underlying the performance of the Hecht vault and have demonstrated that the kinematics at touchdown with the vaulting horse are important with a high initial horizontal velocity required for a successful performance. However, these simple models ignore the effects of other factors on performance and whether such models provide an adequate representation of 
vaulting is questionable. In particular, neither model has included the effect of the hands, shoulder torque, elasticity of the horse and gymnast, and changes in the hip and knee angles during the contact phase. Indeed these factors will influence the mechanics of the contact phase and may affect the conclusions drawn.

The purpose of this study was: [1] to investigate the effects of: the initial kinematics at touchdown with the horse, and during contact, the use of the hands, the elastic properties of the horse and gymnast, hip flexion, knee flexion, and shoulder torque exerted during the contact phase on the performance of the Hecht vault and [2] to investigate the level of complexity required to give an adequate representation of vaulting.

\section{Methods}

A computer simulation model of the horse contact phase in vaulting was developed and was customised to an elite gymnast through the determination of subject-specific inertia and strength parameters. A simulation that matched an actual performance of the Hecht vault by the gymnast was generated. The simulation model was then used to investigate the factors influencing vaulting performance and to assess the level of model complexity required for an adequate representation of vaulting.

Anthropometric measurements of an elite gymnast were taken and segmental inertia parameters were calculated using the mathematical model of Yeadon (1990b). One Hecht vault performance by the gymnast was recorded using a Locam $16 \mathrm{~mm}$ cine camera operating at $200 \mathrm{~Hz}$ and a $50 \mathrm{~Hz}$ video camera. Fifteen body landmarks (wrist, elbow, shoulder, hip, knee, ankle and toe on both sides of the body plus the centre of the head) were digitised manually throughout the movements. A DLT reconstruction (Abdel-Aziz and Karara, 1971) was then used to synchronise the digitised data (Yeadon and King, 1999) and obtain 3D coordinate time histories of each digitised body landmark. The 3D data were used to obtain orientation and configuration angles and quintic splines were fitted (Wood and Jennings, 1979) to determine mass centre velocity and whole body angular momentum about the mass centre (Yeadon, 1990a, c). Strength measurements were taken during eccentric-concentric movements using an isovelocity dynamometer (KinCom 125E) with crank angular velocities ranging from $20^{\circ} \mathrm{s}^{-1}$ to $250^{\circ} \mathrm{s}^{-1}$, in order to express torque as a function of joint angle and angular velocity at the shoulder joint (King and Yeadon, 2002). The gymnast gave informed consent for these procedures in accordance with the protocol approved by the Loughborough University Ethical Advisory Committee.

A planar five-segment model comprising hand, arm, trunk + head, thigh, and shank + foot segments was developed for simulating the contact phase of the hands with the vaulting horse (Figure 1) The visco-elastic properties of the interface between the model and the vaulting horse (arm-horse interface) were represented by two massless non-linear springs (equations in table 4) which joined the end of the arm segment to the vaulting horse and allowed for horizontal and vertical movement of the arm relative to the horse top (Figure 1) The hand segment in the model was represented by these horizontal and vertical springs which allowed the model to remain in contact with the horse until the end of the arm segment was the length of the hands above the horse top. The visco-elastic properties of the glenohumeral joint were represented by a non-linear massless spring which was aligned with the arm segment and joined it to the trunk segment (Figure 1). The model had a (shoulder extensor) torque generator that acted to close the shoulder joint angle (Figure 1) and was allowed to have an initial value of up to $50 \%$ full activation and to remain at this level for a period of time before ramping up to some final level (less than or equal to full activation). The ramping function increased from zero to the final level over a time period greater than or equal to $50 \mathrm{~ms}$. A rotational elastic component with a stiffness value of $1500 \mathrm{Nm} \cdot \mathrm{rad}^{-1}$ was 
included in series with the torque generator and allowed $4 \%$ stretch at maximum torque (personal communication with Van der Helm). The hip and knee angles (Figure 1) were constrained to move in the same way as in the actual Hecht vault performance using the quintic spline fits (Wood and Jennings, 1979).

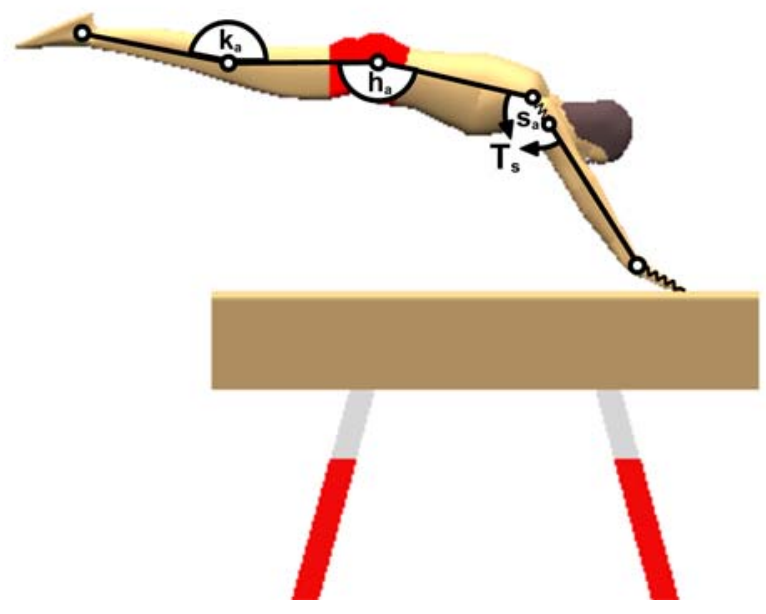

Figure 1. Five-segment simulation model of the contact phase in vaulting. Features include four rigid segments, two springs between the model and the vaulting horse, one spring at the shoulder joint, hip and knee angles specified as functions of time, and a torque generator at the shoulder joint which acts to close the shoulder angle.

The FORTRAN code implementing the model was generated using the Autolev software package which is based on Kane's method of formulating the equations of motion (Kane and Levinson, 1985). Subject-specific model parameters comprised the previously obtained segmental inertias and joint torque parameters. Input to the simulation model comprised the state of the system as the hands made contact with the vaulting horse (mass centre velocity, orientation of each segment, angular velocity of each segment) and four parameters for the torque generator (initial activation, onset time, ramp time, final activation level). The output from the model comprised whole body angular momentum about the mass centre, mass centre velocity, orientation and angular velocity of each segment at the time of takeoff from the vaulting horse. These data at takeoff were used as the initial conditions for an 11-segment simulation model of aerial movement (Yeadon et al., 1990) so that the somersault rotation during flight could be determined. The aerial model required time histories of the configuration angles during flight. A quintic function (Yeadon and Hiley, 2000) at each joint was used over the first $100 \mathrm{~ms}$ to merge the model configuration at takeoff into the configuration of the actual performance. The flight phase ended when the mass centre reached the same height as the actual performance at landing. Consequently the position and orientation at landing of a simulation can be compared directly with the position and orientation at landing of the actual performance with any differences being due to the momenta and body orientation / configuration at takeoff from a simulation.

The Simulated Annealing algorithm (Goffe, et al., 1994) was used to vary 12 parameters in the model in order to obtain a matching simulation which was in close agreement with the image analysis of the recorded Hecht vault performance. The cost function which was minimised was based on the difference between a simulation and the actual performance in terms of strategy $\left(\mathrm{val}_{\mathrm{s}}\right)$ comprising shoulder and trunk angles at takeoff, takeoff $\left(\mathrm{val}_{\mathrm{t}}\right)$ comprising the horizontal and vertical velocity of the mass centre and the whole body angular momentum at takeoff, and elasticity $\left(\mathrm{val}_{\mathrm{e}}\right)$. The elasticity component consisted 
of the maximum horizontal and vertical movement of the wrists, the maximum movement and final position of the shoulders relative to the trunk, and the time of contact. The weightings for each variable in val $_{t}$ and val $_{e}$ were set in proportion to the inverse of the maximum value of each variable from the actual performance. The effect of using these weightings was that $\mathrm{val}_{\mathrm{t}}$ and $\mathrm{val}_{\mathrm{e}}$ represented the average percentage difference between a simulation and an actual performance in terms of the velocity and angular momentum at takeoff, shoulder and wrist movement and time of contact. For the calculation of $\mathrm{val}_{\mathrm{s}}$ the trunk segment angle was given twice the weighting of the shoulder angle since the trunk angle represented the whole body orientation. $\mathrm{val}_{\mathrm{s}}$ measured the difference in the strategy used between a simulation and the actual performance in degrees. The score (cost function) for a simulation was then calculated by averaging $\mathrm{val}_{\mathrm{t}}, \mathrm{val}_{\mathrm{e}}$ and $\mathrm{val}_{\mathrm{s}}$ since $10 \%$ for $\mathrm{val}_{\mathrm{t}}$ or $\mathrm{val}_{\mathrm{e}}$ was considered to be comparable with $10^{\circ}$ for val $_{\text {s. }}$

The initial conditions for the simulation were estimated from the image analysis of the recorded performance and corresponded to the time of initial contact of the hands with the vaulting horse. The initial mass centre velocity and segment angles were fixed at the values estimated from the image analysis as these were considered to be sufficiently accurate. However, the initial angular velocities of the arm and trunk segments were allowed to vary by $\pm 50^{\circ} \mathrm{s}^{-1}$ in the matching optimisation as these estimates were not considered to be so accurate. In addition 10 other parameters were varied in the matching optimisation. Four of these defined the activation time history of the torque generator, four parameters governed the visco-elastic characteristics of the arm-horse interface and two parameters governed the viscoelastic characteristics of the shoulder joint. The Simulated Annealing algorithm was used to vary the 12 parameters within realistic limits until the best match was found.

Perturbations were then introduced to the matching simulation and single simulations were run to establish the effect of each factor on vaulting performance. For shoulder torque two single simulations were run, one with the torque generator switched off and one with the torque generator maximally on. For shoulder elasticity and arm-horse elasticity the stiffness and damping parameters were changed by $\pm 10 \%$ as well as increasing the values so that no movement occurred at the shoulder or arm-horse interface. For hip and knee flexion the two joints were fixed at the initial angles at touchdown and at angles of $180^{\circ}$ at touchdown. For the hands, the hand was removed from the model so that takeoff occurred as the end of the arm segment came away from the horse. The initial conditions at touchdown (shoulder angle and whole body angular momentum) were perturbed in order to produce a handspring simulation (forwards rotating vault). In addition a single simulation was run using the initial conditions from the actual Hecht vault performance and the model constrained to act as a twosegment model (no shoulder torque, hip and knee angles fixed at $180^{\circ}$, no hand, no movement at the shoulder and no movement at the arm-horse interface).

\section{Results and Discussion}

Subject-specific parameters were determined for the elite gymnast used in the study. The inertia parameters consisted of the mass, mass centre location, length and moment of inertia of the four rigid segments in the model (Table 1). The maximum shoulder torque that could be exerted by the gymnast was expressed as a function of shoulder angle and angular velocity (Figure 2). The visco-elastic characteristics of the arm-horse interface and the shoulder joint were determined in the matching procedure as it was not possible to determine them directly (Table 3). 
Table 1. Segmental inertia parameters for the five-segment simulation model

\begin{tabular}{|c|c|c|c|c|}
\hline segment & mass & $\begin{array}{c}\text { mass centre } \\
\text { location } \\
{[\mathrm{m}]}\end{array}$ & $\begin{array}{c}\text { segment } \\
\text { length } \\
{[\mathrm{kg}]}\end{array}$ & $\begin{array}{c}\text { moment } \\
\text { of inertia } \\
{\left[\mathrm{kg} . \mathrm{m}^{2}\right]}\end{array}$ \\
\hline shank+foot & 8.12 & 0.23 & 0.60 & 0.20 \\
\hline thigh & 15.41 & 0.17 & 0.40 & 0.21 \\
\hline trunk+head & 34.45 & 0.36 & 0.52 & 1.62 \\
\hline arm+hand & 7.80 & 0.29 & 0.56 & 0.25 \\
\hline
\end{tabular}

Note: Since the model has single segments representing both feet, lower legs, upper legs and arms the values given are the combined values of both limbs. Mass centre locations measured from the proximal joint and the trunk+head segment length is from hip to shoulder.

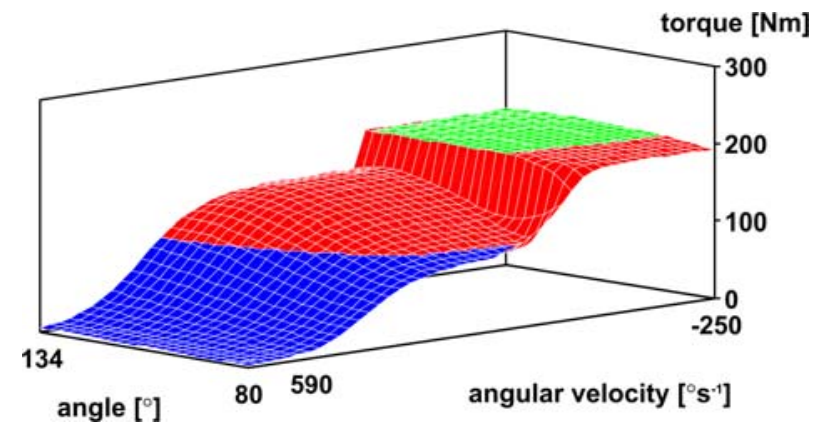

Figure 2. Surface showing maximum torque as a function of the shoulder angle and angular velocity.

Reasonable agreement was found between the actual Hecht vault and the matching simulation ( $\mathrm{val}_{\text {tes }}=7.1$ corresponding to $\mathrm{val}_{\mathrm{t}}=8.9 \%, \mathrm{val}_{\mathrm{e}}=6.3 \%$ and $\mathrm{val}_{\mathrm{s}}=5.7^{\circ}$ ). The initial conditions for the simulation were estimated from the video analysis (Table 2) and the 12 elasticity and activation parameters were varied (Table 3) until the best comparison was found (Table 4). At takeoff from the vaulting horse (fourth graphic in each sequence of (Figure 3) the difference in mass centre velocity was $10 \%$, the difference in angular momentum was $3 \%$, and the average difference in segment angles was $6^{\circ}$ (Table 4). The effect of these differences in takeoff conditions is shown in the last three graphics of each sequence (Figure 3). 
Table 2. Kinematics at initial contact with the vaulting horse

\begin{tabular}{|c|c|c|c|c|c|c|}
\hline $\mathrm{u}_{\mathrm{g}}$ & $\mathrm{v}_{\mathrm{g}}$ & $\mathrm{h}_{\mathrm{g}}$ & $\mathrm{tr}_{\mathrm{a}}$ & $\mathrm{s}_{\mathrm{a}}$ & $\mathrm{h}_{\mathrm{a}}$ & $\mathrm{k}_{\mathrm{a}}$ \\
\hline $5.68 \mathrm{~ms}^{-1}$ & $0.71 \mathrm{~ms}^{-1}$ & $39 \mathrm{~kg} \cdot \mathrm{m}^{2} \cdot \mathrm{rads}^{-1}$ & $5^{\circ}$ & $137^{\circ}$ & $164^{\circ}$ & $179^{\circ}$ \\
\hline
\end{tabular}

Note: All values are at initial contact of the hand with the vaulting horse, $\mathrm{u}_{\mathrm{g}}$ and $\mathrm{v}_{\mathrm{g}}=$ horizontal and vertical velocities of the mass centre, $h_{g}=$ angular momentum about a transverse axis through the mass centre, $\operatorname{tr}_{\mathrm{a}}=$ trunk angle above the horizontal, $\mathrm{s}_{\mathrm{a}}=$ shoulder angle, $\mathrm{h}_{\mathrm{a}}=$ hip angle, $\mathrm{k}_{\mathrm{a}}=$ knee angle.

The overall agreement between the actual performance and the matching simulation was considered to be sufficiently good to allow the subject-specific simulation model to be used to investigate the factors which influence vaulting performance. Although the five-segment simulation model is more complex than previously developed two-segment models, a potential limitation is its simplicity. The assumption of using rigid links, the lack of a rigid hand segment and wrist joint, the lack of active forces to resist movement at the shoulder joint and the lack of shoulder elasticity in line with the body may have jeopardised the accuracy of the model. However, since the matching of the actual performance was reasonably good it is likely that any omissions from the model have only a small effect on performance.

Table 3. Values of the 12 parameters used in the matching simulation

\begin{tabular}{|llc|c|}
\hline \multicolumn{2}{|c|}{ parameter } & value \\
\hline horizontal stiffness $\quad \mathrm{k}_{1}$ & $0.013 \mathrm{kNm}^{-2}$ \\
\hline horizontal damping $\quad \mathrm{k}_{2}$ & $14.6 \mathrm{kNsm}^{-2}$ \\
\hline vertical stiffness & $\mathrm{k}_{3}$ & $25,284 \mathrm{kNm}^{-2}$ \\
\hline vertical damping & $\mathrm{k}_{4}$ & $900 \mathrm{kNsm}^{-2}$ \\
\hline shoulder stiffness & $\mathrm{k}_{5}$ & $345 \mathrm{kNm}^{-2}$ \\
\hline shoulder damping & $\mathrm{k}_{6}$ & $0.27 \mathrm{kNsm}^{-2}$ \\
\hline initial activation & $\mathrm{i}_{\mathrm{s}}$ & $3 \%$ \\
\hline onset time & $\mathrm{t}_{\mathrm{s}}$ & $0.000 \mathrm{~s}$ \\
\hline ramp time & $\mathrm{r}_{\mathrm{s}}$ & $0.240 \mathrm{~s}$ \\
\hline maximum activation & $\mathrm{max}_{\mathrm{s}}$ & $89 \%$ \\
\hline arm angular velocity & $\omega_{\mathrm{a}}$ & $300^{\circ} \mathrm{s}^{-1}$ \\
\hline trunk angular velocity & $\omega_{\mathrm{t}}$ & $190^{\circ} \mathrm{s}^{-1}$ \\
\hline
\end{tabular}

Note: force in each spring $=$ stiffness $\times$ displacement ${ }^{2}+$ damping $\times$ displacement $\times$ velocity 

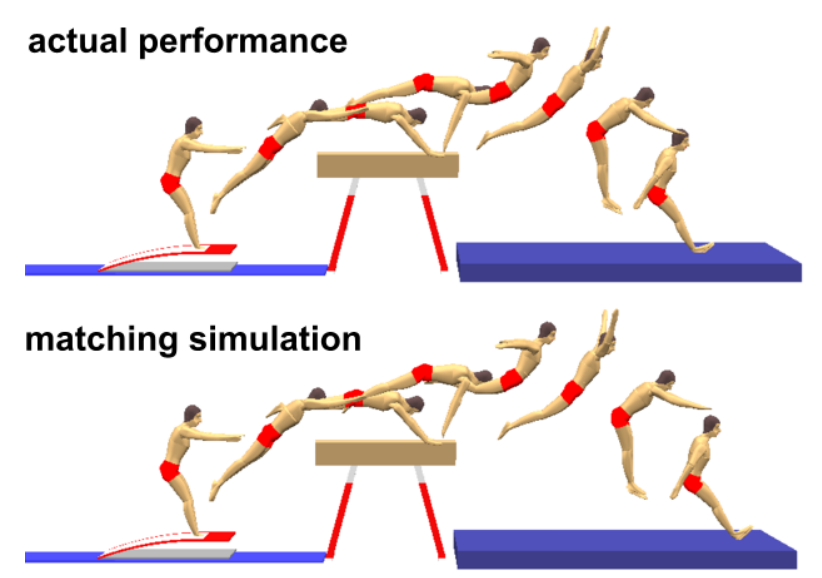

Figure 3. Comparison of actual performance and matching simulation.

Single simulations with the values for individual factors varied in turn from the values used in the matching simulation were used to reveal how sensitive performance was to each factor and to determine the level of complexity needed for an accurate simulation model of vaulting. Fixing the hip and knee angles at their initial values had a small effect with $3^{\circ}$ less rotation than the matching simulation (Figure 4). At takeoff there was a 3\% difference in mass centre velocity and a $4 \%$ difference in angular momentum when compared to the matching simulation (Table 4). When the hip and knee angles were fixed at $180^{\circ}$ during contact similar results were obtained. These small differences suggest that the performance of the Hecht vault is not greatly influenced by changes in the hip or knee angles while in contact with the horse. This is probably a consequence of only small angle changes occurring, since the body should remain extended. Therefore a simulation model of vaulting may not necessarily require separate segments for the thighs and lower legs + feet. 
Table 4. Comparison of actual performance and simulations

\begin{tabular}{|c|c|c|c|c|c|c|c|c|}
\hline variable & $\begin{array}{c}\text { actual } \\
\text { performance }\end{array}$ & $\begin{array}{l}\text { matching } \\
\text { simulation }\end{array}$ & $\begin{array}{l}\text { fixed hip and } \\
\text { knee angles } \\
\text { simulation }\end{array}$ & $\begin{array}{l}\text { no hands } \\
\text { simulation }\end{array}$ & $\begin{array}{l}\text { no shoulder } \\
\text { torque } \\
\text { simulation }\end{array}$ & $\begin{array}{l}\text { maximum } \\
\text { shoulder torque } \\
\text { simulation }\end{array}$ & $\begin{array}{c}\text { stiff shoulder } \\
\text { simulation }\end{array}$ & $\begin{array}{c}\text { two-segment } \\
\text { simulation }\end{array}$ \\
\hline $\mathrm{u}_{\mathrm{g}}$ & $4.01 \mathrm{~ms}^{-1}$ & $4.55 \mathrm{~ms}^{-1}$ & $4.48 \mathrm{~ms}^{-1}$ & $4.56 \mathrm{~ms}^{-1}$ & $4.49 \mathrm{~ms}^{-1}$ & $5.03 \mathrm{~ms}^{-1}$ & $4.22 \mathrm{~ms}^{-1}$ & $3.84 \mathrm{~ms}^{-1}$ \\
\hline $\mathrm{v}_{\mathrm{g}}$ & $1.67 \mathrm{~ms}^{-1}$ & $1.78 \mathrm{~ms}^{-1}$ & $1.85 \mathrm{~ms}^{-1}$ & $2.18 \mathrm{~ms}^{-1}$ & $1.80 \mathrm{~ms}^{-1}$ & $1.36 \mathrm{~ms}^{-1}$ & $1.16 \mathrm{~ms}^{-1}$ & $2.75 \mathrm{~ms}^{-1}$ \\
\hline $\mathrm{h}_{\mathrm{g}}$ & -17.5 & -16.9 & -16.2 & -14.3 & -15.4 & -17.9 & -5.6 & -6.7 \\
\hline $\mathrm{t}$ & $0.169 \mathrm{~s}$ & $0.155 \mathrm{~s}$ & $0.152 \mathrm{~s}$ & $0.096 \mathrm{~s}$ & $0.155 \mathrm{~s}$ & $0.147 \mathrm{~s}$ & $0.153 \mathrm{~s}$ & $0.000 \mathrm{~s}$ \\
\hline $\mathrm{q}_{1 \max }$ & $0.10 \mathrm{~m}$ & $0.10 \mathrm{~m}$ & $0.10 \mathrm{~m}$ & $0.10 \mathrm{~m}$ & $0.10 \mathrm{~m}$ & $0.08 \mathrm{~m}$ & $0.12 \mathrm{~m}$ & $0.00 \mathrm{~m}$ \\
\hline $\mathrm{q}_{2 \max }$ & $0.01 \mathrm{~m}$ & $0.01 \mathrm{~m}$ & $0.01 \mathrm{~m}$ & $0.01 \mathrm{~m}$ & $0.01 \mathrm{~m}$ & $0.01 \mathrm{~m}$ & $0.01 \mathrm{~m}$ & $0.00 \mathrm{~m}$ \\
\hline $\mathrm{q}_{4 \max }$ & $0.11 \mathrm{~m}$ & $0.10 \mathrm{~m}$ & $0.10 \mathrm{~m}$ & $0.10 \mathrm{~m}$ & $0.10 \mathrm{~m}$ & $0.09 \mathrm{~m}$ & $0.00 \mathrm{~m}$ & $0.00 \mathrm{~m}$ \\
\hline $\mathrm{q}_{\text {4end }}$ & $-0.02 \mathrm{~m}$ & $-0.02 \mathrm{~m}$ & $-0.02 \mathrm{~m}$ & $-0.02 \mathrm{~m}$ & $-0.02 \mathrm{~m}$ & $-0.02 \mathrm{~m}$ & $0.00 \mathrm{~m}$ & $0.00 \mathrm{~m}$ \\
\hline $\operatorname{tr}_{a}$ & $10^{\circ}$ & $5^{\circ}$ & $-1^{\circ}$ & $8^{\circ}$ & $5^{\circ}$ & $1^{\circ}$ & $5^{\circ}$ & $5^{\circ}$ \\
\hline $\mathrm{S}_{\mathrm{a}}$ & $78^{\circ}$ & $71^{\circ}$ & $67^{\circ}$ & $99^{\circ}$ & $72^{\circ}$ & $63^{\circ}$ & $74^{\circ}$ & $137^{\circ}$ \\
\hline$l_{\mathrm{a}}$ & $23^{\circ}$ & $18^{\circ}$ & $21^{\circ}$ & $33^{\circ}$ & $26^{\circ}$ & $18^{\circ}$ & $67^{\circ}$ & $60^{\circ}$ \\
\hline
\end{tabular}

Note: $u_{\mathrm{g}}$ and $\mathrm{v}_{\mathrm{g}}=$ the horizontal and vertical velocity of the mass centre at takeoff from the vaulting horse, $\mathrm{h}_{\mathrm{g}}=$ the angular momentum about a transverse axis through the mass centre at takeoff $\left[\mathrm{kg} \cdot \mathrm{m}^{2} \cdot \mathrm{rads}^{-1}\right], \mathrm{t}=$ time of contact, $\mathrm{d}_{\mathrm{hmax}} / \mathrm{d}_{\mathrm{vmax}}=\operatorname{maximum}$ horizontal / vertical depression of the vaulting horse / hand interface, $\mathrm{d}_{\text {smax }} / \mathrm{d}_{\text {send }}=$ maximum / final depression of the shoulders, $\operatorname{tr}_{a}=$ trunk angle above the horizontal at takeoff, $s_{a}=$ shoulder angle at takeoff, $l_{a}=$ orientation of the body at landing relative to the vertical. 

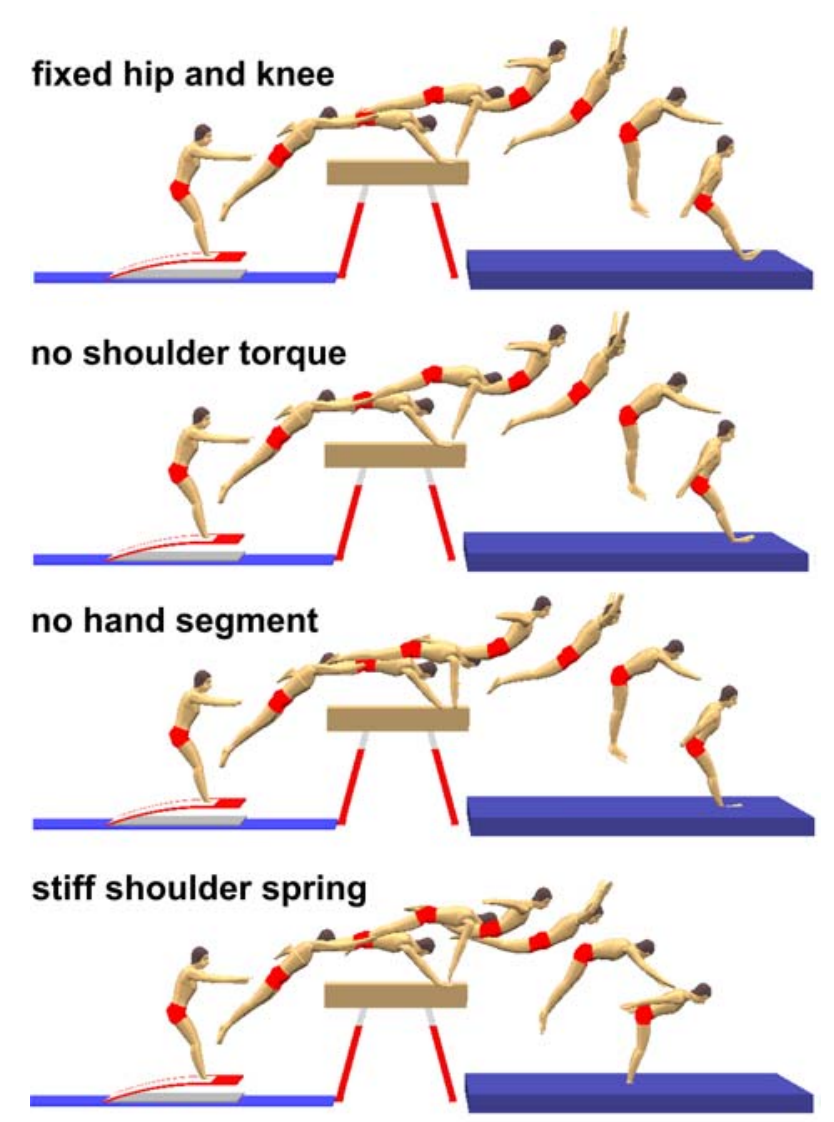

Figure 4. The effect on performance in the Hecht vault of [a] fixed hip and knee angles, [b] no shoulder torque, [c] no hands, and [d] stiff shoulders.

The matching simulation used sub-maximal shoulder torque (30\% of the maximum torque possible during the takeoff phase) and this suggests that the ability of the gymnast to produce shoulder torque may not limit performance in the Hecht vault. Perturbing the shoulder torque used during the contact phase had only a small effect on performance. Increasing the shoulder torque to maximum throughout the contact phase resulted in a somewhat lower trunk angle, lower vertical mass centre velocity, and greater backwards angular momentum at takeoff (Table 4), while removing shoulder torque resulted in a slightly higher vertical velocity and less backwards angular momentum at takeoff (Table 4, Figure 4). The reason for the similar simulations is that in the Hecht vault, the shoulder angle decreases rapidly during the contact phase, and therefore the muscles producing shoulder torque are under concentric conditions for the whole of the contact phase. As a consequence relatively small torques can be produced during the Hecht vault and therefore perturbing the shoulder torque has only a small effect on performance. A simulation model of vaulting should include representations of the torques produced by muscles crossing the shoulder since gymnasts do try to use shoulder torque to aid the performance of the Hecht vault and in other vaults where the shoulder joint is not closing rapidly, shoulder torque may have a greater influence on performance.

Perturbing the initial shoulder angle and the initial whole body angular momentum had a large effect on performance, with a handspring (forwards rotating) vault being possible (Figure 5). It was found that a smaller initial shoulder angle at touchdown produced more backwards rotation during the contact phase whereas a larger initial shoulder angle produced the opposite. Changing the shoulder angle from $137^{\circ}$ to $180^{\circ}$ so that the arms were in line 
with the body and increasing the initial whole body angular momentum by $25 \%$ gave the model sufficient angular momentum at takeoff to produce a handspring vault. Thus the type of vault that can be performed depends on the initial kinematics at touchdown with the horse. For example, a Hecht vault cannot be performed if the shoulder angle is close to $180^{\circ}$ at touchdown.

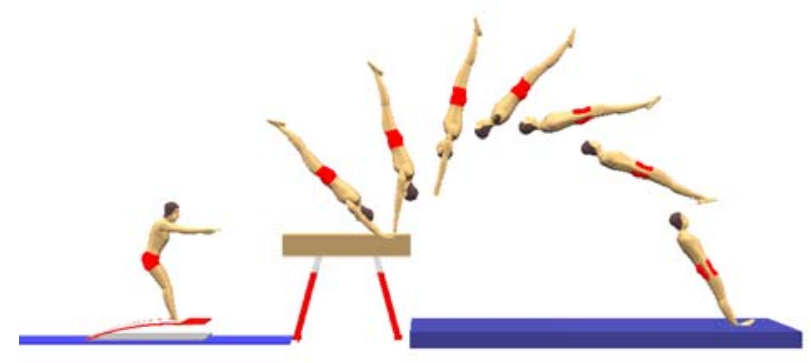

Figure 5. Perturbation of the initial conditions in the matching simulation to produce a handspring vault.

Ending the simulation of the contact phase when the end of the arm came away from the horse (no hand) meant that the reaction force acting through the arm had less time to produce torque about the mass centre and consequently the angular momentum at takeoff (backwards somersault rotation) was $15 \%$ smaller resulting in $15^{\circ}$ less backwards rotation than the matching simulation (Figure 4). Clearly the hands should be represented in a simulation model of vaulting, as they allow the model to remain in contact with the horse for longer, resulting in greater angular momentum. However, in terms of understanding the fundamental mechanics of vaulting, the hands play a minor role and hence the two-segment models developed previously are able to demonstrate the general principles involved in vaulting.

Varying the shoulder and arm-horse visco-elastic parameters by $\pm 10 \%$ had small effects that resulted in landing orientations that were less than $5^{\circ}$ different from the matching simulation. However, increasing the shoulder stiffness and damping so that no movement occurred at the shoulder resulted in a very different simulation. At takeoff there was a 35\% reduction in the vertical velocity of the mass centre and a $67 \%$ reduction in angular momentum when compared with the matching simulation, resulting in $50^{\circ}$ less rotation (Table 4, Figure 4). Thus a simulation model of vaulting should permit translational movement at the shoulder joint since otherwise there is a substantial energy loss with a concomitant reduction in performance.

Constraining the five-segment simulation model to emulate a two-segment model (single simulation with the same initial conditions as calculated from the actual performance) resulted in an instantaneous takeoff, a high vertical velocity and reduced angular momentum, giving $42^{\circ}$ less backwards rotation in flight (Table 4). This simulation demonstrates the major limitation of simple two-segment models, in that it is unrealistic to expect a simple model to be able to simulate an actual performance accurately. Therefore a simple model cannot be used to determine optimum approach velocity, for example, but can be used to understand some of the basic principles involved in vaulting. For example, a simple twosegment model of vaulting is sufficiently complex to explain the changes in linear and angular momentum during horse contact. The velocity of the shoulder joint in the direction of the arm is reduced to zero and so there is a reaction force along the arm which reduces the horizontal 
velocity, increases the vertical velocity, and produces a torque about the mass centre tending to rotate the body backwards.

The implications of the results for gymnasts are that touchdown orientation and configuration are crucial, the ability to resist shoulder compression is important, as is maintaining hand contact for as long as possible. From a modelling perspective the use of a more complex five-segment simulation model confirms the fundamental findings of previous two-segment models that the use of shoulder torque plays a minor role in vaulting performance whereas having appropriate initial kinematics at touchdown is essential. However, some of the factors ignored in the two-segment models, such as shoulder elasticity and a hand segment, also have a major influence on performance. As a consequence unless a simple model can be shown to give an accurate representation of a sports movement, any quantitative results should only be taken to indicate order of magnitude effects.

\section{Acknowledgments}

The financial support of the Biotechnology and Biological Sciences Research Council (BBSRC) and the cooperation of British Gymnastics are gratefully acknowledged.

\section{References}

Abdel-Aziz, Y.I., Karara, H.M., 1971. Direct linear transformation from comparator coordinates into object-space coordinates. (ASP Symposium on Close-Range Photogrammetry). Falls Church, VA: American Society of Photogrammetry. pp. 1-18.

Fédération Internationale de Gymnastique. (1993). Compulsory Exercises: MEN 1993-1996. Switzerland: FIG.

Fink, H., Zschoke, K.H., 1994. New criteria for the performance of the compulsory vault. Memorandum to all Gymnastics Federations from the Men's Technical Committee.

Kane, T.R., Levinson, D.A., 1985. Dynamics: Theory and applications, McGraw-Hill Book Company, New York.

King, M.A., Yeadon, M.R., Kerwin, D.G., 1999. A two segment simulation model of long horse vaulting. Journal of Sports Sciences, 17, 313-324.

King, M.A., Yeadon, M.R., 2002. Determining subject specific torque parameters for use in a torque driven simulation model of dynamic jumping. Journal of Applied Biomechanics, 18, 195-206.

Sprigings, E.J., Yeadon, M.R., 1997. An insight into the reversal of rotation in the Hecht vault. Human Movement Science, 16, 517-532.

Wood, G.A., Jennings, L.S., 1979. On the use of spline functions for data smoothing. Journal of Biomechanics, 12, 477-479.

Yeadon, M.R., 1990a. The simulation of aerial movement - I: The determination of orientation angles from film data. Journal of Biomechanics, 23, 59-66.

Yeadon, M.R., 1990b. The simulation of aerial movement - II: A mathematical inertia model of the human body. Journal of Biomechanics, 23, 67-74.

Yeadon, M.R., 1990c. The simulation of aerial movement - III: The determination of the angular momentum of the human body. Journal of Biomechanics, 23, 74-83. 
Yeadon, M.R., Atha, J., Hales, F.D., 1990. The simulation of aerial movement - IV: A computer simulation model. Journal of Biomechanics, 23, 85-89.

Yeadon, M.R., King, M.A., Sprigings, E.J., 1998. Pre-flight characteristics of Hecht vaults. Journal of Sports Sciences, 16, 349-356.

Yeadon, M.R., Hiley, M.J., 2000. The mechanics of the backward giant circle on the high bar. Human Movement Science, 19, 153-173. 